\title{
СОВРЕМЕННОЕ СОСТОЯНИЕ И ПРОБАЕМЫ ФОРМИРОВАНИЯ СИСТЕМ ТОПАИВНО-ЭНЕРГЕТИЧЕСКОГО ОБЕСПЕЧЕНИЯ В АРКТИЧЕСКИХ РЕГИОНАХ РОССИИ
}

\begin{abstract}
Аннотауия. Несмотря на преобладание в экономической спеииализаиии российских арктических регионов отраслей, так или иначе связанных с энергетикой, проблема их топливно-энергетического обеспечения, как особой категории потребителей внутреннего энергетического рынка, по-прежнему сохраняет свою высокую актуальность. Џелью исследования стало выявление современных тенденций изменения транспортно-

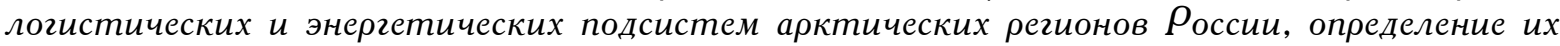
возможностей и признаков адаптации $\kappa$ новым вызовам и условиям социальноэкономического развития страны. Для достижения поставленной иели применяются методы количественного и качественного анализа, экспертные оченки. В основу методологии исследования положен территориально-отраслевой подход. В качестве информационной базы исследования использованы результаты работ российских и зарубежных спе-

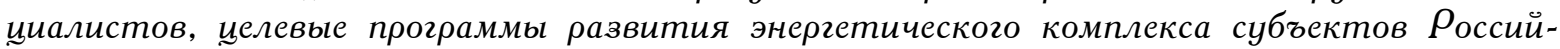

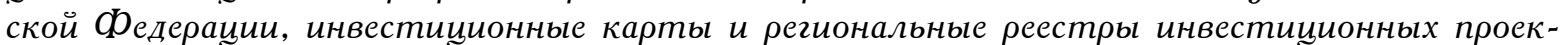
тов. Определены основные направления дальнейшего формирования в Арктике региональных транспортных энергетических подсистем как части национального транспортного и энергетического комплексов. Установлено, что модернизащия арктического газотранспортного комплекса и территориальная газификация стали одним из базовых направлений совершенствования региональной энергетики. Рассмотрен практический опыт реализаиии транспортно-энергетических проектов в российской Арктике. Определено, что в проиессах формирования территориальной инфраструктуры арктических регионов утвердился выраженный дисбаланс инвестиционного обеспечения между программами развития промышленно-отраслевой и мунищипальной энергетики. Дана оценка готовности территориальной топливно-энергетической и транспортной инфраструктуры $\kappa$ обеспечению крупных инвестищионных проектов в Арктике. Работа адресована научным сотрудникам, специалистам органов региональной власти и местного самоуправления, представителям транспортного и энергетического комплекса, жилищно-коммунального хозяйства, а также всем тем, кто интересуется проблематикой по теме обеспечения

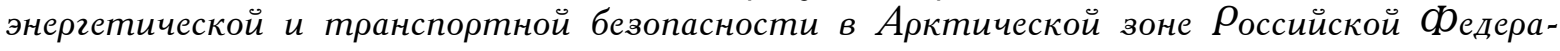
uиu.
\end{abstract}

Ключевые слова: Россия, Арктика, инфраструктура, топливо, транспорт, инвестиции.

BIEV ALEXANDER ANATOLIEVICH

Ph. D. in Economics, senior researcher of the Institute of economic problems named. G. $P$. Luzina, Federal research center" Kola scientific center of $R A S »$, e-mail: biyev@mail.ru

\section{CURRENT STATE AND PROBLEMS OF FORMATION FUEL AND ENERGY SUPPLY SYSTEMS IN THE ARCTIC REGIONS OF RUSSIA}

Abstract. Despite the predominance in the economic specialization of the Russian Arctic regions of industries, one way or another related to energy, the problem of their fuel and energy supply, as a special category of consumers of the domestic energy market, still retains its high relevance. The purpose of the study was to identify current trends in transport, logistics and energy subsystems of the Arctic regions of Russia, to determine their capabilities and signs of adaptation to new challenges and conditions of socio-economic development of the country. To achieve this goal, 
methods of quantitative and qualitative analysis, expert assessments are used. The research methodology is based on the territorial-sectoral approach. The results of the work of Russian and foreign experts, target programs for the development of the energy complex of the subjects of the Russian Federation, investment maps and regional registers of investment projects were used as an information base of the study. The main directions of further formation of regional transport energy subsystems in the Arctic as part of the national transport and energy complexes are determined. It is established that the modernization of the Arctic gas transportation complex and territorial gasification have become one of the basic directions of improving regional energy. Practical experience of implementation of transport and energy projects in the Russian Arctic is considered. It is determined that in the processes of formation of the territorial infrastructure of the Arctic regions, a pronounced imbalance of investment support between the programs of development of industrial and municipal energy was established. The readiness of the territorial fuel and energy and transport infrastructure to support major investment projects in the Arctic is assessed. The work is addressed to researchers, specialists of regional authorities and local governments, representatives of the transport and energy complex, housing and communal services, as well as all those who are interested in the problems of ensuring energy and transport security in the Arctic zone of the Russian Federation.

Keywords: Russia, Arctic, infrastructure, fuel, transport, investments.

Введение. Вопросы формирования инновационного энергетического комплекса стали одними из наиболее актуальных направлений технологического и социально-экономического развития в Арктической зоне России (АЗ РФ) [1]. Особенно пристальное внимание уделяется потенциальным возможностям передела и трансформации мирового рынка топливноэнергетических поставок, которые возникают на фоне обострения межстрановой геоэкономической, геополитической и технологической конкуренции в мировой Арктике [2]. В основе целеполагания комплекса лежат государственные задачи обеспечения сырьевого экспорта, рационализации внутренних перевозок топливно-энергетических ресурсов, обеспечения национальной транспортной и энергетической безопасности. Стратегия его развития очерчена рамками разрабатываемой еще с советских времен концепции единой арктической транспортной системы. В ней определена главенствующая роль Северного морского пути (СМП) и обеспечивающих его транспортных подходов в построении схем межрегиональных и трансконтинентальных путей сообщения [3]. Обеспечение реализации концепции в ее актуализированном варианте невозможно без дальнейшего усиления инфраструктурного потенциала арктических регионов. В целом схожие мнения высказываются в ряде работ российских исследователей $[4$, 5]. Однако, кроме развития в Арктике отраслевой энергетики, немаловажное значение имеют задачи развертывания локальной энергетической инфраструктуры, модернизации муниципальных энергетических систем. На повестку дня поставлены давно назревшие вопросы развития внутреннего энергетического рынка, межрегиональных транспортно-экономических связей, улучшения качества жизни местного населения, что означает первоочередную необходимость решения сопутствующих проблем его энергоснабжения [6]. Формирование территориальных систем обеспечения поставок топлива соответствует рамкам известной концепции цикличности развития экономических, технологических и иных систем, изложенной в трудах иностранных [7] и российских ученых [8]. Тенденции их изменения, в первую очередь, обусловлены численностью проживающего в данном регионе населения, уровнем производства в реальном секторе. Вместе с тем транспортно-энергетические процессы в условиях российской и мировой Арктики имеют ряд характерных особенностей, свойственных малонаселенным территориям с недостаточной диверсификацией экономики, транспортной и инфраструктурной освоенностью $[9,10]$. Особое признание на мировом уровне получил статус Арктики как региона с уязвимой экологией, в наибольшей степени подверженной антропогенному воздействию [11]. Интенсивные климатические изменения, происходящие в нем, в частности, рост среднегодовых температур, таяние арктических льдов, смещение на север зон вечной мерзлоты, становятся ключевым фактором, влияющим на изменение конфигурации энергетических сетей, наземных и водных коммуникаций, зон арктического морского судоходства, интенсивность транспортных перевозок [12]. 
Отсутствие развитой региональной дорожной инфраструктуры, возможностей обеспечения круглогодичной навигации и выхода на федеральную систему магистрального транспортного сообщения обусловили необходимость государственного регулирования процессов построения транспортно-экономических связей территорий Арктической зоны России с центральными районами страны. В отношении арктических регионов установлен особый режим государственной социально-экономической политики [13]. В табл. 1 указаны данные о различных видах транспорта, используемого для завоза и распределения топливных ресурсов в АЗ РФ. Важно отметить крайне неравномерный характер развития российского арктического транспортного комплекса. Тем не менее в ходе организации и осуществления арктических топливных поставок применяются почти все виды транспорта. На разных этапах поставок, осуществляемых на регулярной основе, транспортировка топливных ресурсов происходит по железной дороге, водным (морским и внутренним речным) транспортом. Для материально-технического снабжения временных вахтовых поселков, расположенных в изолированных промышленных районах, а также в особых случаях при возникновении угроз чрезвычайных ситуаций, связанных с нарушением штатных режимов функционирования систем территориального жизнеобеспечения, привлекается авиация. Автомобильный транспорт используется, в основном, в рамках начально-конечных логистических операций распределения топлива с нефтебаз, пунктов временного или сезонного хранения. В арктических районах Северо-Западного и Уральского федеральных округов межрегиональные автомобильные перевозки топлива осуществляются по технологическим сезонным и временным автомобильным дорогам.

Таблица 1

\section{Виды топливных ресурсов и способы их доставки на территорию арктических регионов России*}

\begin{tabular}{|c|c|c|c|c|}
\hline \multirow{2}{*}{$\begin{array}{l}\text { Вид } \\
\text { транспорта }\end{array}$} & \multicolumn{4}{|c|}{ Арктическая зона России } \\
\hline & $\begin{array}{c}\text { Мурманская } \\
\text { область }\end{array}$ & Ненецкий $А О$ & Ямало-Ненецкий АО & Чукотский АО \\
\hline Трубопроводный & - & Природный газ** & Природный газ & Природный газ** \\
\hline Железнодорожный & $\begin{array}{l}\text { Нефтепродукты, } \\
\text { уголь, сжиженный } \\
\text { углеводородный газ }\end{array}$ & - & Нефтепродукты, уголь & - \\
\hline Водный & - & $\begin{array}{l}\text { Нефтепродукты, } \\
\text { уголь }\end{array}$ & $\begin{array}{l}\text { Нефтепродукты, уголь, } \\
\text { сжиженный природный } \\
\text { газ }\end{array}$ & $\begin{array}{l}\text { Нефтепродукты, } \\
\text { уголь }\end{array}$ \\
\hline Автомобильный & - & $\begin{array}{l}\text { Нефтепродукты, } \\
\text { уголь }\end{array}$ & Нефтепродукты, уголь & - \\
\hline Авиационный & - & - & - & - \\
\hline
\end{tabular}

*Источник: составлено автором по данным действующих региональных программ развития транспортного комплекса арктических субъектов РФ.

** На территории региона действует локальная газотрубопроводная система.

Использование магистральных схем доставки находится в прямой зависимости от степени транспортной освоенности территорий, наличия местной топливной базы, объектов локального энергетического производства [14]. Схемы поставок доминирующих в Арктике топливноэнергетических ресурсов - нефтепродуктов и угля - предусматривают системообразующую роль морского и железнодорожного транспорта [15]. Территориальная железнодорожная инфраструктура регионов центральной части России, Дальневосточного и Северо-Западного федеральных округов обеспечивает процессы промежуточного транзита, накопления и перевалки наиболее массовых грузов «северного завоза» - топлива, продовольствия, промышленного оборудования и строительных материалов. Совместно с водной доставкой режим применения железнодорожного транспорта в системе материально-технического снабжения арктических территорий характеризуется наибольшей протяженностью транспортных расстояний [16]. Дальнейшее наращивание транспортно-экономического потенциала арктических территорий, 
непосредственно связанного с осуществлением крупных, инвестиционно емких инфраструктурных проектов, в первую очередь, таких, как «Мурманский транспортный узел», «Северный широтный ход» и «Белкомур», будет усиливать роль сети железнодорожных коммуникаций в обеспечении перевозок традиционных топливно-энергетических ресурсов в российской Арктике.

Основные объемы поставок газового топлива для местных потребителей с месторождений на территории Ненецкого, Ямало-Ненецкого и Чукотского автономных округов (АО) осуществляются по локальным газотранспортным системам. Связь арктического газотранспортного комплекса с Единой системой газоснабжения Российской Федерации осуществляется через систему магистральных газопроводов, проложенных по территории Ямало-Ненецкого АО. В Мурманской области газодобывающая и газотрубопроводная инфраструктура полностью отсутствует. Тем не менее планам территориальной газификации и перевода коммунальных энергетических предприятий с иных видов топлива на природный газ во всех арктических регионах уделяется значительное внимание. За последние два года в стадию практической реализации вступил проект дальнейшего развития локальной газопроводной системы в Чукотском автономном округе. Реализованы пилотные проекты строительства модульных газовых котельных в Мурманской и Архангельской областях, Республике Карелия. Ведутся подготовительные работы для возведения газопроводов-отводов, сети межпоселковых газопроводов в арктических районах Республики Саха (Якутия), а также Республики Коми. Газификация арктических территорий имеет своей приоритетной целью оказать положительное влияние на решение одних из наиболее острых проблем социально-экономического развития - сдерживания роста тарифов в сфере коммунального теплоснабжения и обновления основных фондов предприятий теплоэнергетики.

Методы и материалы исследования. Для достижения целей исследования применялись экспертные методы познания, использовалась методология системного анализа, территориально-отраслевого подхода. В работе используются следующие общие методы научных исследований: индукция, дедукция, анализ и синтез. Благодаря использованию этих методов, обеспечивается научный характер выполненной работы. В качестве информационной базы исследования использованы публикации российских и зарубежных специалистов, данные инвестиционных карт и региональных реестров инвестиционных проектов арктических субъектов Российской Федерации.

Результаты. Наличие значительного объема научных изысканий, имеющих своей целью поиск возможностей совершенствования региональных систем снабжения, пока не привело к переходу на путь комплексного решения указанных проблем. Несмотря на вступление России в этап практического осуществления в Арктике т. н. «мегапроектов», большинство из которых обладает транспортно-энергетической специализацией, значительная часть муниципальных энергетических потребностей арктических субъектов по-прежнему закрывается за счет организации сезонных централизованных поставок с опорой на регионы с развитой нефтегазоперерабатывающей промышленностью. Использование цифровых технологий, электронных баз данных инвестиционных проектов, размещаемых в сети Интернет на официальных порталах региональных органов власти арктических субъектов Российской Федерации, помогает оценить текущие и перспективные процессы формирования важнейших элементов территориальной энергетической инфраструктуры. В табл. 2 на основании анализа данных, представленных в инвестиционных картах и реестрах инвестиционных проектов арктических регионов, показано, что модернизация газотранспортного комплекса стала одним из базовых направлений совершенствования региональных энергетических систем. Основной поток инвестиций направлен на обеспечение развития арктической нефтегазодобывающей и перерабатывающей промышленности.

Экономический рост, наблюдаемый в нефтегазовой и нефтегазотранспортной отрасли, безусловно, влияет на развитие планов модернизации локальной энергетики. В арктических и приарктических районах рассматриваются перспективные возможности газификации территорий муниципальных образований, примыкающих к магистральным маршрутам морской и трубопроводной транспортировки газа. В Ямало-Ненецком, Ненецком, и Чукотском автономных округах действуют государственные и региональные целевые программы территориальной 
газификации. Показатели их финансирования в масштабах всех инвестиций, привлекаемых в развитие национального газотранспортного комплекса в Арктике, остаются незначительными. По результатам оценки, выполненной автором, общий портфель целевых инвестиционных проектов, направленных на развитие арктических газотранспортных систем, составляет более 367 млрд руб. Он занимает долю порядка 10,2\% суммарного объема всех инвестиционных проектов транспортно-энергетической направленности в АЗ РФ (см. строку 3 в табл. 2). Доля включенных в эти расходы финансовых средств, предусмотренных для реализации программ территориальной газификации арктических муниципальных районов и их коммунальных объектов, оценивается в размере порядка $0,9 \%$ (около 3,14 млрд руб.). Столь низкая доля социально-значимых инвестиций на фоне гигантских затрат, вливаемых в создание отраслевых транспортно-энергетических систем, дает основания говорить о том, что появление крупных компаний, ведущих хозяйственную деятельность в центрах арктической добычи и переработки сырья, пока мало способствует в создании трендов модернизации социально-значимых энергетических объектов. В процессах формирования территориальной инфраструктуры арктических регионов утвердился выраженный дисбаланс инвестиционного обеспечения между программами развития промышленной и локальной муниципальной энергетики.

Таблица 2

Основные направления проектов развития энергетической и транспортноэнергетической инфраструктуры в Арктической зоне России на период до 2025 г.*

\begin{tabular}{|c|c|c|}
\hline \multirow{2}{*}{$\begin{array}{c}\text { № } \\
\Pi / \Pi\end{array}$} & \multicolumn{2}{|c|}{ Проекты развития энергетической инфраструктуры в Арктической зоне России } \\
\hline & Содержание направления & $\begin{array}{c}\text { Доля в общем } \\
\text { финансировании, \% }\end{array}$ \\
\hline 1 & Возведение промышленных объектов переработки нефти и газа & 45.1 \\
\hline 2 & $\begin{array}{l}\text { Обустройство новых и поддержание уровня добычи на уже действующих нефтегазовых } \\
\text { месторождениях }\end{array}$ & 42.6 \\
\hline 3 & $\begin{array}{l}\text { Строительство и реконструкция объектов газотранспортных систем, территориальной } \\
\text { газификации жилого фонда и производственных предприятий }\end{array}$ & 10.2 \\
\hline 4 & $\begin{array}{l}\text { Строительство новых объектов энергоснабжения, производства и передачи электро- } \\
\text { энергии }\end{array}$ & 1.1 \\
\hline 5 & Строительство котельных, использующих биотопливо, организация его производства & 0.9 \\
\hline 6 & $\begin{array}{l}\text { Реконструкция теплоэнергетического комплекса, инженерных коммуникаций и тепло- } \\
\text { вых сетей }\end{array}$ & 0.1 \\
\hline & $\begin{array}{l}\text { Справочно, общий объем финансового обеспечения транспортно-энергетических инве- } \\
\text { стиционных проектов в Арктической зоне России, млрд руб. }\end{array}$ & 3602.5 \\
\hline
\end{tabular}

*Источник: региональные реестры инвестиционных проектов арктических субъектов Российской Федерации; составлено и рассчитано автором.

В аналитической литературе, посвященной вопросам становления транспортноэнергетической инфраструктуры в Арктике, встречаются экспертные позиции, отстаивающие тезис о том, что базовые цели реализации арктических «мегапроектов» изначально не были ориентированы на решение локальных вопросов энергообеспечения, поэтому нет достаточных оснований ожидать их достижения и в ближайшей перспективе $[17,18]$. В конечном итоге, наиболее востребованные в социально-экономическом плане (например, проект освоения Штокмановского газоконденсатного месторождения) и, одновременно, наиболее инвестиционно емкие дальнейшего развития не получили [19]. Чтобы обеспечить производственную деятельность в новых районах промышленного освоения, изолированных от сетей централизованного снабжения, прошла дополнительную реструктуризацию или была создана заново топливно-энергетическая база отдельных групп промышленных потребителей [20]. Прежде всего, они представлены объектами добывающих отраслей.

Выводы. Таким образом, значительных изменений в составе ключевых объектов арктической коммунальной энергетической инфраструктуры, основных схем завоза, распределения 
топлива, источников поставок в ближайшей перспективе не произойдет. Последовательная трансформация территориальной энергетики, направленная на достижение узкоотраслевых задач, оказало крайне слабое влияние на процессы развития и модернизации муниципальных энергетических систем. Значительно актуализировался целый комплекс проблем, связанный с энергетическим обеспечением социально-значимых групп потребителей арктических регионов.

Лuтература

1. Елистратов, В. В. Энергетический, экологический и соџиально-экономический аспекты в энергоснабжении северных и арктических территорий РФ [Текст] // Экологический вестник России. 2017. №11. C. 30-35.

2. Dudin, M. N., Lyasnikov, N. V., Sekerin, V. D., Gorohova, A. E., Danko, T. P., Bank, O. A. Technological changes as the development factor of the global and Russian energy sector // International Journal of Energy Economics and Policy. 2017. Vol. 7 (1). P. 209-215.

3. Боякова, С. И. Дискуссия о подходах к развитию транспортной системы северных территорий СССР в 1920-е г2. [Текст] // Природные ресурсы Арктики и Субарктики. 2014. № 3. С. 9-13.

4. Северные территории в общероссийском, региональном, муниципальном пространстве ; под науч. ред. д. э. н. Т. П. Скуфьиной : моногр. - Апатиты : КНЦ РАН, 2012

5. Факторный анализ и прогноз грузопотоков Северного морского пути ; науч. ред. д. э. н., проф. Селин В. С., д. э. н., проф. Козьменко С. Ю. - Anатитьл : КНЦ РАН, 2015.

6. Васильев, В. В., Грицевич, А. В., Селин, В. С. Исторические тенденции и современные организационно -экономические проблемы «северного завоза». - Anатиты : КНЦ РАН, 2009.

7. Madlener, R., Alcott, B. Energy rebound and economic growth : a review of the main issues and research needs // Energy. 2009. No. 34. P. 370-376.

8. Конторович, А. Э., Эпов, М. И., Эдер, Л. В. Долгосрочные и среднесрочные факторы и сиенарии развития глобальной энергетической системы в ХХІ веке [Текст] // Геология и геофизика. 2014. T. 55. № 5 -6. C. 689-700.

9. Гасникова, А. А. Состояние, проблемы и перспективы развития энергоснабжения арктических районов России [Текст] // Север и рынок : формирование экономического порядка. 2017. № 3 (59). С. 69-77. 10. Patin, S. Offshore Oil and Gas Production and Transportation / Salomon M., Markus T. (eds) // Handbook on Marine Environment Protection. - Springer, Cham, 2018. P. 149-164. DOI: https://doi.org/10.1007/978-3319-60156-4 8 .

11. Smedsrud, L. H., Ingvaldsen, R., Nilsen, J. E., Skagseth, O. Heat in the Barents Sea : transport, storage, and surface fluxes // Ocean Science. 2010. No. 6. P. 219-234.

12. Лексин, В. Н., Порфирьев, Б. Н. Специифика трансформаичи пространственной системы и стратегии переосвоения российской Арктики в условиях изменений климата // Экономика региона. 2017. T. 13. Bbin. 3. C. 641-657. DOI: 10.17059/2017-3-1.

13. Биев, А. А. Формирование системы топливно-энергетического обеспечения северных территорий России [Электронный ресурс] / А. А. Биев, А. В. Шпак // Управление экономическими системами: электронный научный журнал. 2012. № 6 (42). - URL : http://uecs.ru/uecs42-422012/item/1380-2012-06-05-0658-01 (дата обращения 20.02.2019).

14. Samarina, V., Skufina, T., Samarin, A., Ushakov, D. Alternative Energy Sources : Opportunities, Experience and Prospects of the Russian Regions in the Context of Global Trends // International Journal of Energy Economics and Policy. 2018. Vol. 8. Issue 2. P. 140-147. - URL : https://www.econjournals.com/ index.php/ijeep/article/viewFile/6273/3612 (accessed 20.02.2019).

15. Кондратов, Н. А. Особенности развития транспортной инфраструктуры в Арктической зоне России // Географический вестник = Geographical bulletin. 2017. № 4 (43). C. 68-80. DOI: 10.17072/20797877-2017-4-68-80.

16. Биев, А. А. Проблемы нефтепродуктообеспечения арктических регионов России [Текст] / A. A. Биев, А. В. Шиак // Проблемы развития территории. 2017. № 2 (88). С. 51-62.

17. Комков, Н. И., Сутягин В. В., Володина Н. Н. Необходимость целевого подхода к освоению Арктики [Текст] // МИР (Модернизация. Инновачии. Развитие). 2015. Т. 6. № 4. С. 78-87.

18. Glukhareva, E. K. Prospects for the production and transportation of oil and gas resources from the western Russian Arctic // Stud. Russ. Econ. Dev. 2011. No. 22. P. 507. - URL : https://doi.org/10.1134/ S1075700711050030.

19. Регионы Севера и Арктики Российской Федерации : современные тендениии и перспективы развития : монография ; под науч. редакцией д.э.н., проф. Т.П. Скуфьиной, к.э.н. Н.А. Серовой. - Апатитьл : КНЦ РАН, 2017.

20. Курочкин, А. К. Малье установки для производства дизтоплив из газоконденсатов и малосернистых нефтей [Текст] / А. К. Курочкин, В. С. Шиикин // Сфера Нефтегаз. 2014. №1 (39). С. 54-65.

\section{References:}

1. Elistratov, $V . V$. Energeticheskij, ekologicheskij i social'no-ekonomicheskij aspekty v energosnabzhenii severnyh i arkticheskih territorij RF [Tekst] // Ekologicheskij vestnik Rossii. 2017. №11. S. 30-35.

2. Dudin, M. N., Lyasnikov, N. V., Sekerin, V. D., Gorohova, A. E., Danko, T. P., Bank, O. A. Technological changes as the development factor of the global and Russian energy sector // International Journal of Energy Economics and Policy. 2017. Vol. 7 (1). P. 209-215. 
3. Boyakova, S. I. Diskussiya o podhodah k razvitiyu transportnoj sistemy severnyh territorij SSSR v 1920-e gg. [Tekst] // Prirodnye resursy Arktiki i Subarktiki. 2014. № 3. S. 9-13.

4. Severnye territorii v obshcherossijskom, regional'nom, municipal'nom prostranstve; pod nauch. red. d. e. n.

T. P. Skufinoj : monogr. - Apatity : KNC RAN, 2012.

5. Faktornyj analiz i prognoz gruzopotokov Severnogo morskogo puti ; nauch. red. d. e. n., prof. Selin V. S., d. e. n., prof. Koz'menko S. YU. - Apatity : KNC RAN, 2015.

6. Vasil'ev, V. V., Gricevich, A. V., Selin, V. S. Istoricheskie tendencii i sovremennye organizacionnoekonomicheskie problemy «severnogo zavoza». - Apatity : KNC RAN, 2009.

7. Madlener, R., Alcott, B. Energy rebound and economic growth : a review of the main issues and research needs // Energy. 2009. No. 34. P. 370-376.

8. Kontorovich, A. E., Epov, M. I., Eder, L. V. Dolgosrochnye i srednesrochnye faktory i scenarii razvitiya global'noj energeticheskoj sistemy v XXI veke [Tekst] // Geologiya i geofizika. 2014. T. 55. № 5-6. S. 689-700. 9. Gasnikova, A. A. Sostoyanie, problemy i perspektivy razvitiya energosnabzheniya arkticheskih rajonov Rossii [Tekst] // Sever i rynok: formirovanie ekonomicheskogo poryadka. 2017. № 3 (59). S. 69-77.

10. Patin, S. Offshore Oil and Gas Production and Transportation / Salomon M., Markus T. (eds) // Handbook on Marine Environment Protection. - Springer, Cham, 2018. P. 149-164. DOI: https://doi.org/10.1007/978-3319-60156-4 8 .

11. Smedsrud, L. H., Ingvaldsen, R., Nilsen, J. E., Skagseth, O. Heat in the Barents Sea : transport, storage, and surface fluxes // Ocean Science. 2010. No. 6. P. 219-234.

12. Leksin, V. N., Porfir'ev, B. N. Specifika transformacii prostranstvennoj sistemy $i$ strategii pereosvoeniya rossijskoj Arktiki v usloviyah izmenenij klimata // Ekonomika regiona. 2017. T. 13. Vyp. 3. S. 641-657. DOI: 10.17059/2017-3-1.

13. Biev, A. A. Formirovanie sistemy toplivno-energeticheskogo obespecheniya severnyh territorij Rossii [Elektronnyj resurs] / A. A. Biev, A. V. SHpak // Upravlenie ekonomicheskimi sistemami: elektronnyj nauchnyj zhurnal. 2012. № 6 (42). - URL : http://uecs.ru/uecs42-422012/item/1380-2012-06-05-06-58-01 (data obrashcheniya 20.02.2019).

14. Samarina, V., Skufina, T., Samarin, A., Ushakov, D. Alternative Energy Sources : Opportunities, Experience and Prospects of the Russian Regions in the Context of Global Trends // International Journal of Energy Economics and Policy. 2018. Vol. 8. Issue 2. P. 140-147. - URL : https://www.econjournals.com/index.php/ ijeep/article/viewFile/6273/3612 (accessed 20.02.2019).

15. Kondratov, N. A. Osobennosti razvitiva transportnoj infrastruktury v Arkticheskoj zone Rossii // Geograficheskij vestnik $=$ Geographical bulletin. 2017. № 4 (43). S. 68-80. DOI: 10.17072/2079-7877-2017-4-6880 .

16. Biev, A. A. Problemy nefteproduktoobespecheniya arkticheskih regionov Rossii [Tekst] / A. A. Biev, A. V. SHpak // Problemy razvitiya territorii. 2017. № 2 (88). S. 51-62.

17. Komkov, N. I., Sutyagin V. V., Volodina N. N. Neobhodimost' celevogo podhoda k osvoeniyu Arktiki [Tekst] // MIR (Modernizaciya. Innovacii. Razvitie). 2015. T. 6. № 4. S. 78-87.

18. Glukhareva, E. K. Prospects for the production and transportation of oil and gas resources from the western Russian Arctic // Stud. Russ. Econ. Dev. 2011. No. 22. P. 507. - URL : https://doi.org/10.1134/ S1075700711050030.

19. Regiony Severa i Arktiki Rossijskoj Federacii : sovremennye tendencii i perspektivy razvitiya : monografiya; pod nauch. redakciej d.e.n., prof. T.P. Skuf'inoj, k.e.n. N.A. Serovoj. - Apatity : KNC RAN, 2017.

20. Kurochkin, A. K. Malye ustanovki dlya proizvodstva diztopliv iz gazokondensatov $i$ malosernistyh neftej [Tekst] / A. K. Kurochkin, V. S. SHishkin // Sfera Neftegaz. 2014. №1 (39). S. 54-65. 